\title{
Relative Clause and Downstep in Japanese
}

\author{
Manami Hirayama and Hyun Kyung Hwang \\ Seikei University, RIKEN
}

\section{Introduction}

The pitch register of an accentual phrase is lowered after an accented accentual phrase in Japanese (e.g., Kubozono 1989, Pierrehumbert and Beckman 1988, Poser 1984). This prosodic process is called downstep. It has been proposed that the domain of this process is an Intonational Phrase (IP) or Major Phrase (MP): At the beginning of a new IP/MP, downstep is blocked (see Igarashi 2015 and Ishihara 2015 for a review). The process is particularly important in the syntax-phonology interface and has been reported to be sensitive to certain syntactic information, although research regarding the effect of syntactic information is quite limited. For example, Selkirk and Tateishi (1991) argue that the left edges of maximal projections of syntactic categories blocks downstep. In other words, maximal projections of XPs are mapped onto the left edges of the IP/MP. Ishihara (2016) finds that the left edge of the predicate VP variably blocks downstep.

Moreover, parts of speech have been found to affect downstep differently. Selkirk and Tateishi (1991) argue that downstep occurs when adjective phrases are involved, while it is blocked when noun phrases are involved. Hirayama and Hwang (2016), however, find the opposite: With noun phrases in which two phrases modify the head noun in the right-branching structure $\left[\mathrm{X}_{1}\left[\mathrm{X}_{2} \mathrm{~N}\right]\right]$, downstep was observed when the modifiers were both NPs [ $\left[\mathrm{N}_{1}-n o\left[\mathrm{~N}_{2}-n o \mathrm{~N}\right]\right]$, whereas no downstep was observed when the modifiers were adjectives $\left[A_{1}\left[A_{2} N\right]\right]$. Given this finding, Hirayama and Hwang (2016) propose an analysis that relates the syntactic difference between nouns and adjectives to their syntactic patterns: (Attributive) adjectives project relative clauses in Japanese (Kuno 1973) but nouns modifying other nouns with the particle -no do not; and the clause boundary present in the former blocks downstep. In other words, they propose that the left edge of a relative clause is mapped onto the left edge of an IP/MP, which blocks downstep.

In this paper, expanding on Hirayama and Hwang's (2016) proposal, we conduct a production experiment to investigate whether the relative clause boundary blocks downstep in Japanese. The paper is organized as follows. In the next section, we discuss the methodology of the experiment. In Section 3, we report the results, where it will be shown that the relative clause boundary does not block downstep. Section 4 gives an analysis of the results. Section 5 is a brief summary.

\section{The hypothesis, predictions, and methodology}

As discussed in Section 1, Hirayama and Hwang (2016) found that downstep occurs in noun phrases in which nouns modify the head noun $\left[\mathrm{N}_{1}-n o\left[\mathrm{~N}_{2}-n o \mathrm{~N}\right]\right]$ whereas it does not occur in those NPs in which the modifiers are adjectives $\left[\mathrm{A}_{1}\left[\mathrm{~A}_{2} \mathrm{~N}\right]\right]$. The adjectives were in non-past tense forms with the ending $-i$. They propose that this pattern may be explained based on the difference between adjectives and nouns that adjectives inflect in Japanese; adjectives project relative clauses whereas nouns do not (Kuno 1973), and downstep is sensitive to the relative clause boundary. Following their proposal, our working hypothesis is that relative clause boundaries block downstep in Japanese.

In order to test the hypothesis, we conducted a production experiment. The test sentences are given in (1) and (2). The acute accent indicates lexical accent. In (1), the targets are in the past tense forms of adjectives, as in (1a) (darúkatta), or verbs, as in (1b) (niránda); i.e., they all project a relative clause. In contrast, the targets in (2) are in predicates and thus there are no clause boundaries appear before them. For this condition also, we prepared adjective targets, as in (2a) (nemúi), and verb targets, as in (2b) (nirámu). If

\footnotetext{
${ }^{*}$ We thank the audience of LabPhon 2016 and AMP 2018 for their comments. Special thanks go to Takaomi Kato, whose comments tremendously helped augment the discussion section of the paper. All errors are ours.
} 
the relative clause boundary blocks downstep, the targets in (1) would not be downstepped while those in (2) would, since there is a relative clause boundary before the targets in (1) but not in (2).
Topic
Trigger
Target
head $N$
a. áni-wa $\quad\left[[\text { niránda }]_{\mathrm{RC}} \quad[\text { darúkatta }]_{\mathrm{RC}}\right.$ magó $\left.]\right]_{\mathrm{N}}$ brother-TOP stare(v).PAST tired(ADJ).PAST grandchild COMP say.PAST '(My) brother said a grandchild who stared disfavorably and was tired.'
b. áni-wa [[najínda $]_{\mathrm{RC}} \quad\left[[\text { niránda }]_{\mathrm{RC}}\right.$ magó $\left.]\right]_{\mathrm{NP}}$ to itta brother-TOP adjust(v).PAST stare(v).PAST grandchild COMP say.PAST

'(My) brother said a grandchild who adjusted themselves and stared disfavorably.'

(2)
Topic
Trigger
Target
a. áni-wa [magó-ga nemúi] brother-TOP grandchild-NOM sleepy(ADJ).NONPAST '(My) brother said the grandchild is sleepy.'
$\begin{array}{ll}\text { to } & \text { itta } \\ \text { COMP } & \text { say.PAST }\end{array}$
b. áni-wa [magó-ga nirámu $]$ to itta brother-TOP grandchild-NOM stare(v).NONPAST COMP say.PAST '(My) brother said the grandchild stares (at him) disfavorably.'

To judge whether downstep was present, we followed the literature (Kubozono 1989, Pierrehumbert and Beckman 1988, Poser 1984) and prepared comparative sentences, as shown in (3). They were the same as (1) and (2) in terms of the syntactic structure and the number of moras, but the "triggers" were unaccented (instead of accented) and thus were not in a downstep environment. Recall from Section 1 that the presence of accentedness triggers this process. For example, the sentences in (3a) and (3b), which have unaccented words (mananda 'study(v).PAST,' megunda 'give alms(v).PAST') in the "trigger" position, were paired with (1a) and (1b), respectively. The targets in (1a) and (1b) were judged as downstepped if the pitch was lower than the targets in (3a) and (3b), respectively. Similarly, the sentences in (2a) and (2b) were paired with (4a) and (4b), respectively, where the trigger is unaccented mee-ga 'niece- NOM.' If the f0 peaks in (2a) and (2b) were lower than those in (4a) and (4b), respectively, we judged them as indicating downstep. Two sentences were prepared for each of the structures, totaling sixteen sentences. The full list of sentences is provided in the Appendix.
Topic
Trigger
Target
head $N$

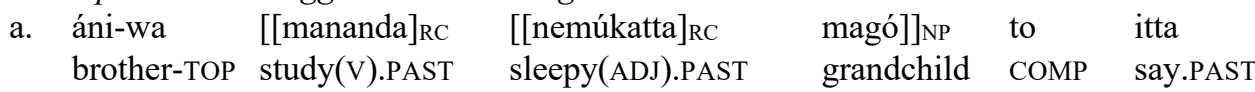
'(My) brother said a grandchild who studied and was sleepy.'
b. áni-wa $\left[[\text { megunda }]_{\mathrm{RC}}\left[[\text { niránda }]_{\mathrm{RC}} \text { magó }\right]\right]_{\mathrm{NP}}$ to itta brother-TOP give alms(v).PAST stare(v).PAST grandchild COMP say.PAST '(My) brother said a grandchild who did alms and stared disfavorably.'

(4)
Topic
Trigger
Target
a. áni-wa [mee-ga nemúi]
brother-TOP niece-NOM sleepy(AD)
'(My) brother said (his) niece is sleepy.'
$\begin{array}{ll}\text { to } & \text { itta } \\ \text { COMP } & \text { say.PAST }\end{array}$
b. áni-wa [mee-ga nirámu $]$ to itta brother-TOP niece-NOM stare(v).NONPAST COMP say.PAST
'(My) brother said (his) niece stares (at him) disfavorably.'

A note is in order. In (1) and (3), the triggers are verbs whether the target is an adjective or verb. It would have been better to use the same category within the same NP, i.e., an adjective for (1a) and (3a), but this 
was not possible because the past tense form of adjectives is always accented; we cannot test whether downstep occurs if the trigger is always accented, since we can judge whether downstep occurs only when we have a comparable sentence where the trigger is unaccented. ${ }^{1}$

Twelve speakers of Tokyo Japanese participated and read eight lists; each list had test sentences in a different order. The recording was made in a studio with sound-attenuated walls. A unidirectional dynamic headset microphone (SHURE SM10A; frequency response: 50-15,000 Hz) and a digital recorder (Marantz PMD661) with a 44,100 Hz sampling rate and 24-bit quantization were used. Two participants were removed from the analysis; one had braces disturbing her speech, while the other was removed due to unnaturally fast speech, presumably from nervousness. This left us ten speakers (nine females) for analysis. The peak f0s of the phrases (labelled Topic, Trigger, Target, and head $N$ in (1) to (3)) were measured using ProsodyPro (Xu 2013), and f0 perturbation was fixed manually when observed. To examine whether the targets were downstepped, linear mixed-effects analyses were performed on the relation between the peak f0s of the target and the trigger accentuation (accented or unaccented) using R (ver. 3.1.2) and the lmerTest package. The speaker and item were entered into the model as random effects; random intercepts and random slopes were included for speaker while random intercepts were included for item.

\section{Results: The relative clause boundary does not block downstep in Japanese}

The results of the statistical analyses are given in. In all cases the accentedness of the trigger had a significant effect on the peak f0 values $(p<.05$ for $(2 a) /(4 a), p<.001$ for $(1 a) /(3 a),(1 b) /(3 b)$, and $(2 b) /(4 b))$, with the estimated $\mathrm{f} 0$ means for the unaccented condition being higher (e.g., by $7.976 \mathrm{~Hz}$ for (3a) compared to (1a)). This suggests that downstep occurred in all conditions, regardless of whether there is a relative clause boundary before the target, as in $(1 \mathrm{a}, \mathrm{b})$, or not, as in $(2 \mathrm{a}, \mathrm{b})$. Also, downstep was observed in both phrases involving adjectives, as in (1a) (2a), and verbs, as in (1b) (2b), although we will return to the category issue in Section 4.

\begin{tabular}{|c|c|c|c|c|}
\hline Type & & $\beta$-coefficient $(\mathrm{Hz})$ & $t$ & $p$ \\
\hline \multirow[t]{2}{*}{ +RC, Adj. (1a) vs. (3a) } & (intercept) & 235.296 & 15.12 & $1.05 \mathrm{e}-07 * * *$ \\
\hline & TriggerUnaccented & 7.976 & 3.51 & $0.000552 * * *$ \\
\hline \multirow[t]{2}{*}{$+\mathrm{RC}$, Verb (1b) vs. $(3 \mathrm{~b})$} & (intercept) & 226.066 & 16.285 & $5.51 \mathrm{e}-08 * * *$ \\
\hline & TriggerUnaccented & 11.336 & 6.061 & $0.000188 * * *$ \\
\hline \multirow[t]{2}{*}{-RC, Adj. (2a) vs. (4a) } & (intercept) & 214.751 & 16.587 & $2.76 \mathrm{e}-08 * * *$ \\
\hline & TriggerUnaccented & 13.717 & 3.615 & $0.0167 *$ \\
\hline \multirow[t]{2}{*}{-RC, Verb (2b) vs. (4b) } & (intercept) & 214.108 & 17.535 & $2.79 \mathrm{e}-08 * * *$ \\
\hline & TriggerUnaccented & 15.738 & 6.192 & $0.000167 * * *$ \\
\hline
\end{tabular}

Table 1 Results of statistics

Figure 1 and Figure 2 give the (raw) means of f0 peak values for the ten speakers. Solid lines indicate f0 peaks in sentences with accented triggers and dotted lines with unaccented triggers. We can see that the values are always higher for the dotted lines at the target, suggesting that downstep is present.

\footnotetext{
${ }^{1}$ This diagnostic for downstep (making comparisons with sentences with unaccented triggers) is called paradigmatic (Ito and Mester 2013) and applied in such studies as Kubozono (1989) and Poser (1984). Another definition of downstep is also found in the literature that relies on a syntagmatic diagnostic (e.g., Selkirk and Tateishi 1991).
} 


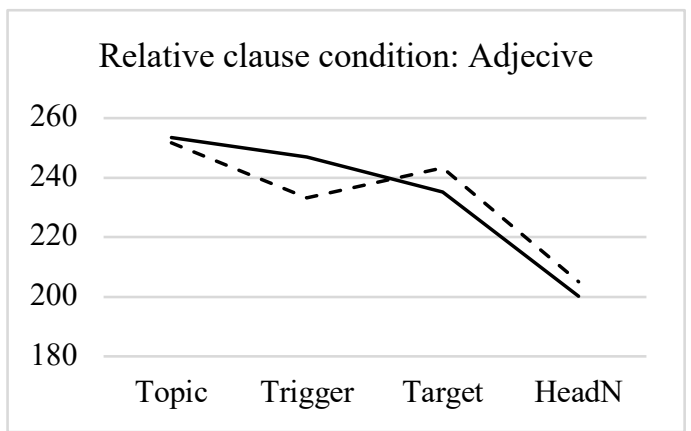

Adjective condition

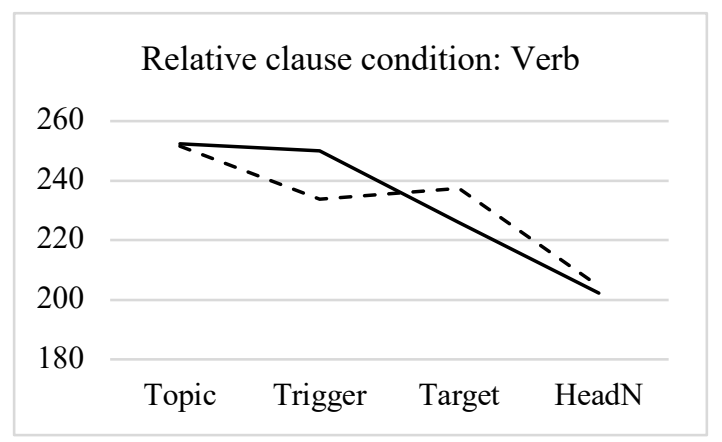

Verb condition

Figure 1 Raw means of f0 peaks (for ten speakers) in $\mathrm{Hz}$, relative clause condition (solid line: accented trigger, dotted line: unaccented trigger)

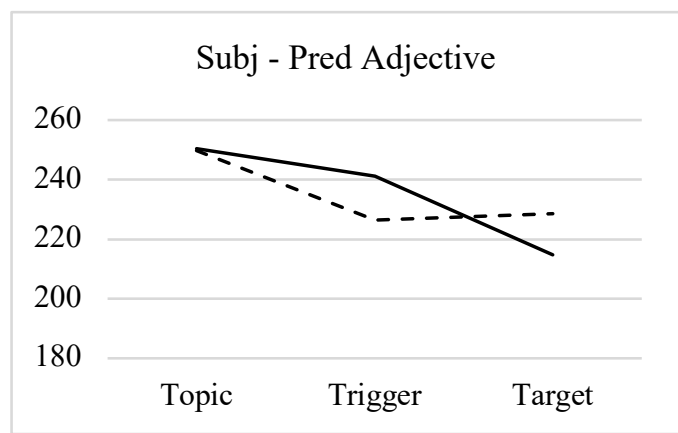

Adjective condition

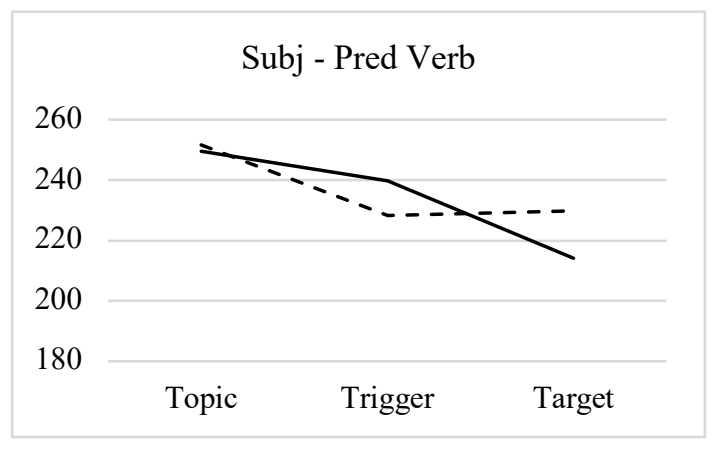

Verb condition

Figure 2 Raw means of f0 peaks (for ten speakers) in Hz, non-relative clause (subject-predicate VP) condition (solid line: accented trigger, dotted line: unaccented trigger)

To summarize the results, downstep was found in all conditions, indicating that the relative clause boundary does not block downstep in Japanese.

\section{Discussion: Adjectives may not really behave the same as verbs in downstep}

In Section 3 we found that the relative clause boundary does not block downstep in Japanese (nor does the boundary between the subject and the predicate VP). In this section, we discuss the issue of syntactic category. As discussed in Section 1, category has long been a topic of discussion as a blocking factor in downstep in Japanese. Selkirk and Tateishi (1991) argued that downstep occurs in NPs involving adjective modifiers but not in NPs involving noun modifiers, whereas Hirayama and Hwang (2016) found the opposite: Downstep occurs in [N-no [N-no N]] but is blocked in [A [A N]]. In this study, we did not find a category difference between adjectives (A) and verbs (V) when the mixed-effects analyses were performed (). However, if we look at individual results, a difference emerges between the two categories. Although interspeaker variability is accounted for in the results in, it is important to discuss the results by individual, as this reveals that the results are more robust in the verb condition than in the adjective condition.

First, we focus on the non-relative clause condition (i.e., (2) and (4)). Graphs in Figure 3 give the mean f0 peak values in Hertz for the ten speakers. Solid lines indicate values for accented triggers and dotted lines those for unaccented triggers. In these graphs, adjectives and verbs are not distinguished, i.e., there are two solid lines and two dotted lines in each graph. However, the lines lie very close to each other within each pair, which suggests that adjectives and verbs do not differ much within the speaker (and within the same accent condition). 


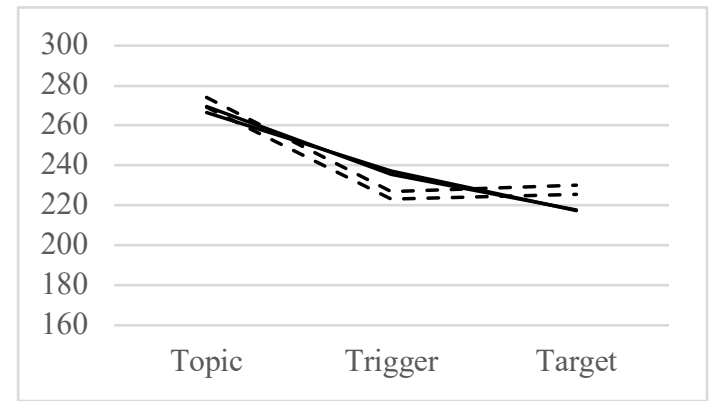

Speaker AK (predicative)

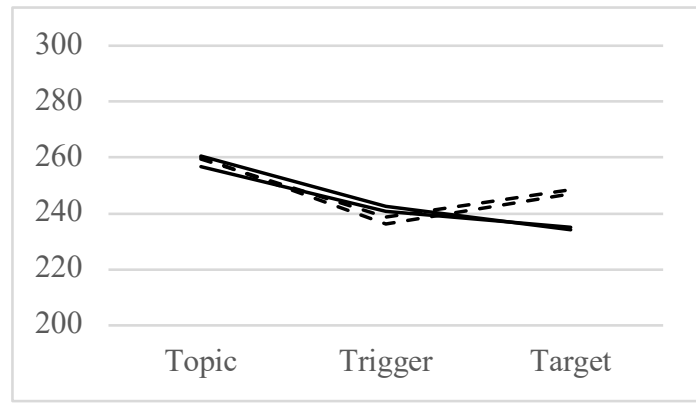

Speaker BB (predicative)

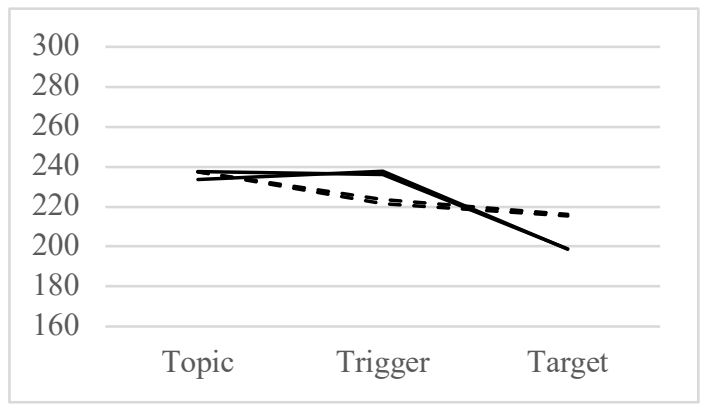

Speaker KT (predicative)

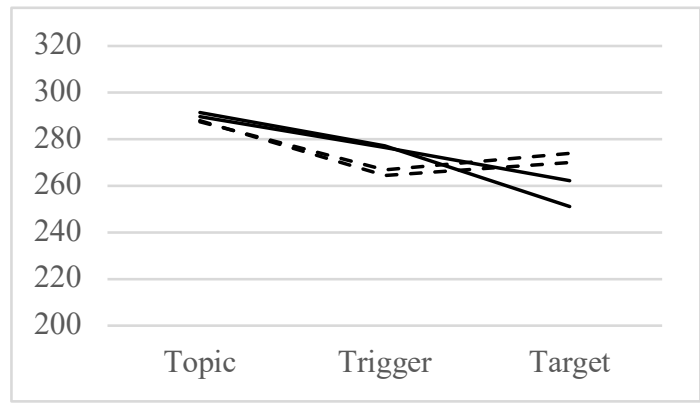

Speaker MR (predicative)
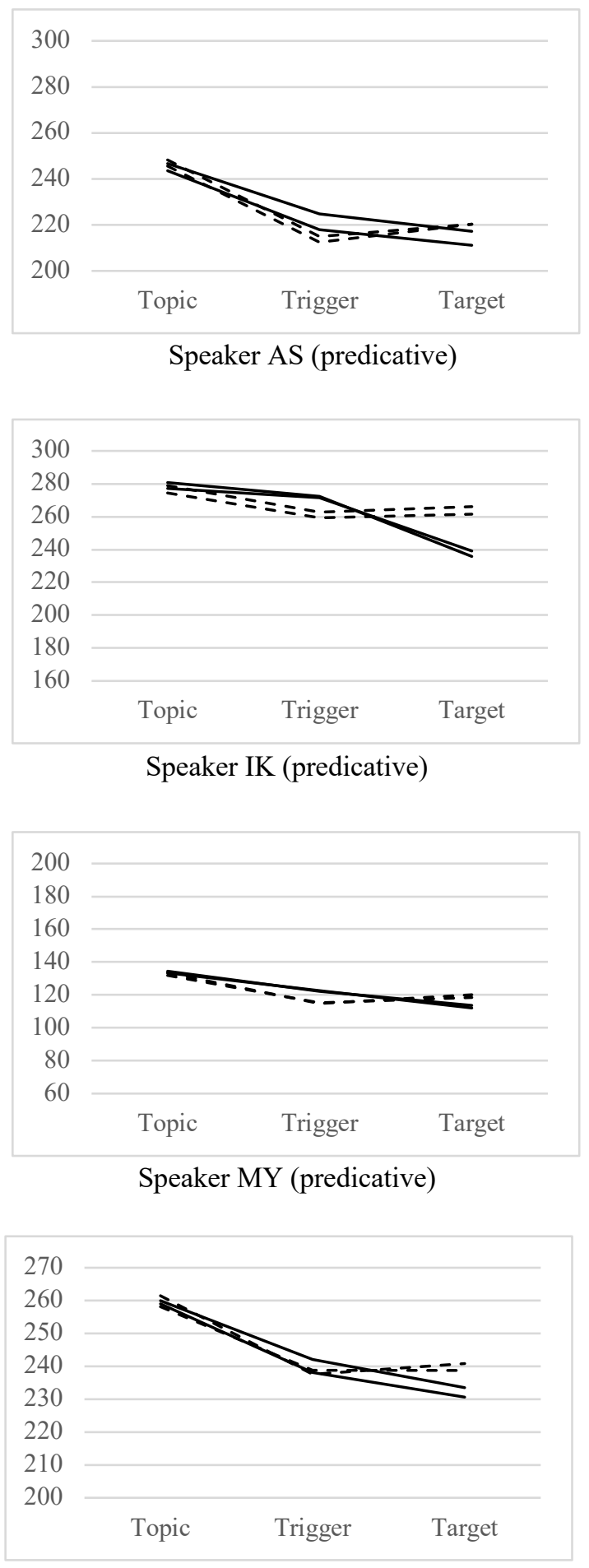

Speaker TK (predicative) 


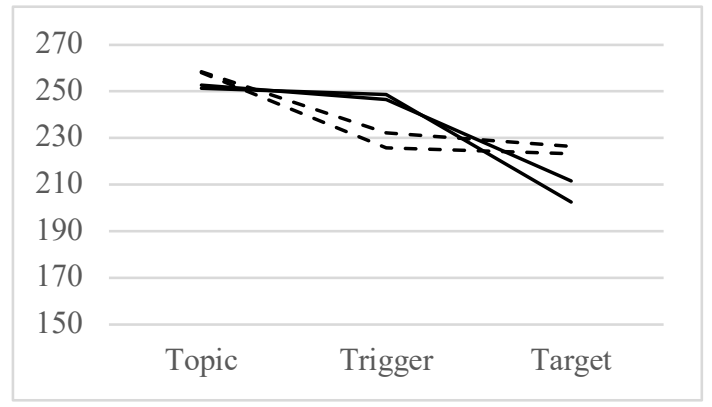

Speaker TR (predicative)

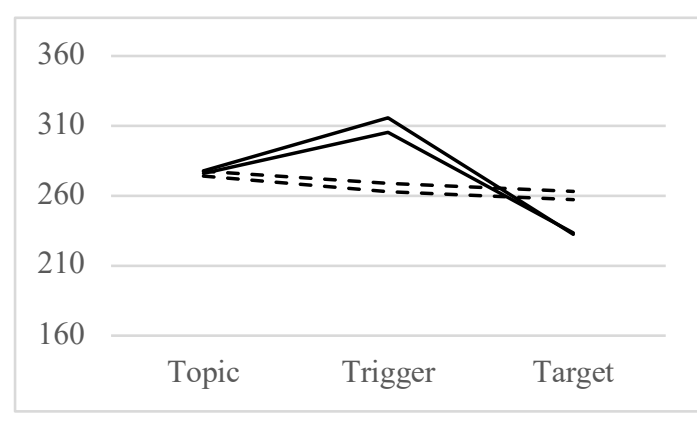

Speaker UD (predicative)

Figure 3 F0 peaks for individual speakers (predicative condition)

Figure $\mathbf{4}$ contains graphs plotting mean f0 peak values in the relative clause condition. On the left are the graphs for adjective targets, and on the right those for verb targets. They show a marked contrast with the graphs in Figure 3 in that there is a consistent pattern across speakers in verbs, whereas inter-speaker variation is found in adjectives. In verbs, most speakers have a higher $\mathrm{f} 0$ value in the dotted line than in the solid line at the target position, suggesting the presence of downstep, and the discrepancy between the solid and dotted lines is relatively large. Speakers AS and MY should be noted as having a relatively small gap between the two lines, although they still follow the overall pattern that the dotted line lies above the solid line at the target. In other words, there is downstep in the verb condition that is robust with very limited speaker variation. In contrast, that is not the case with adjectives. First, there is a speaker (speaker TR) for whom the peak $\mathrm{f0}$ is lower for the dotted line than the solid line in the target position; although the gap is not great, this pattern does not at all appear in sentences with verb targets. Furthermore, only barely half of the speakers (speakers AK, BB, KT, and TK) show a relatively large difference between the two lines in the expected direction (dotted line above solid line, indicating the presence of downstep). In other words, there is much more inter-speaker variability in the adjective condition than in the verb condition.

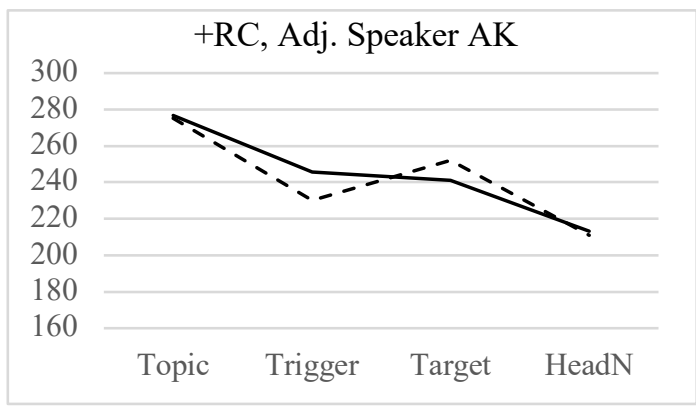

Adjective condition

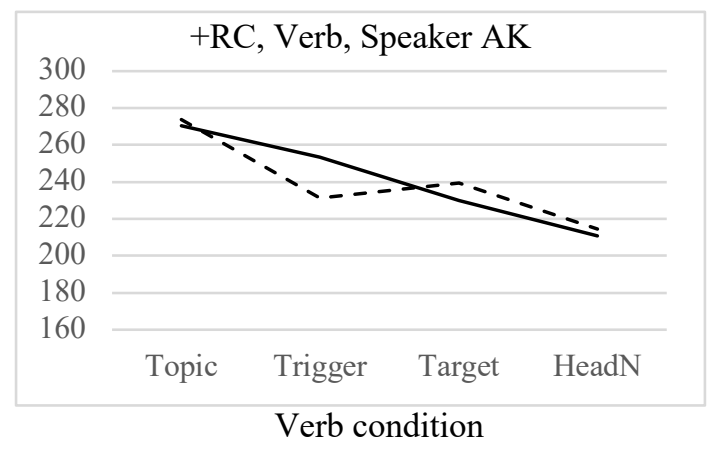

Speaker AK (attributive)

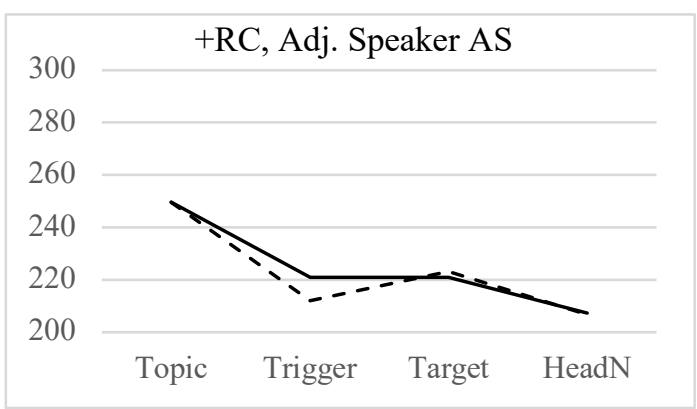

Adjective condition

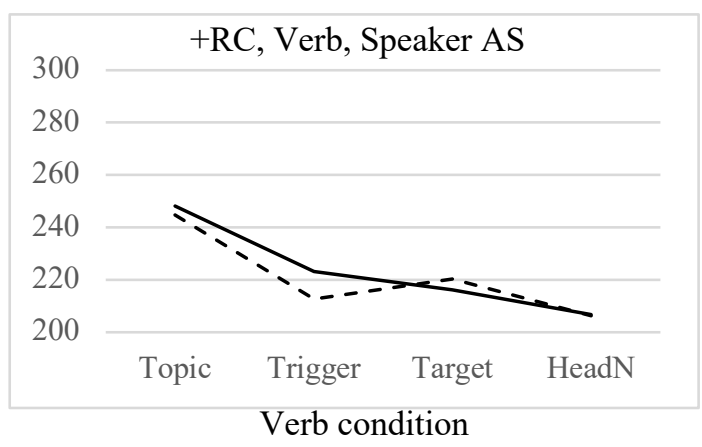

Speaker AS (attributive) 


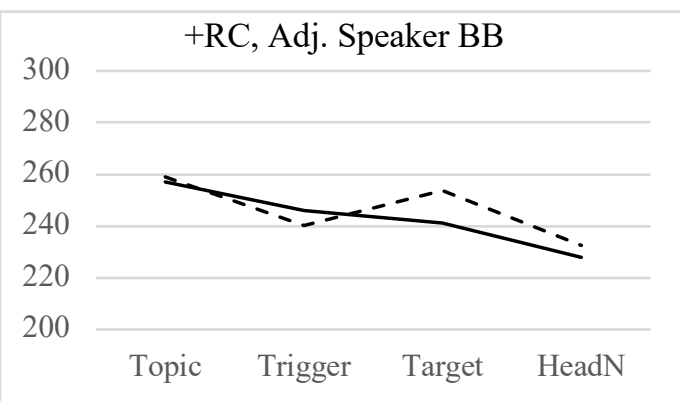

Adjective condition

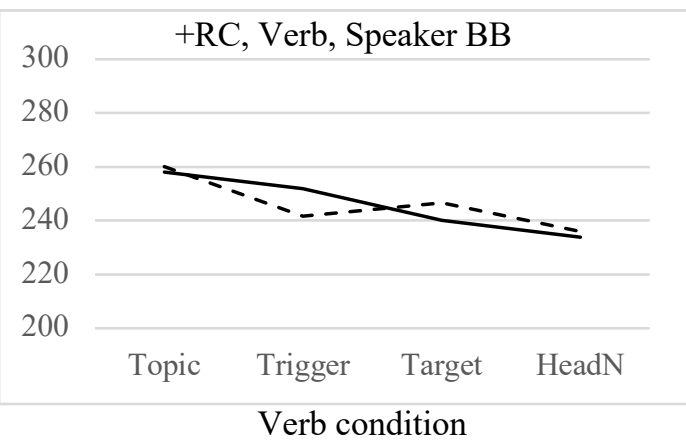

Speaker BB (attributive)

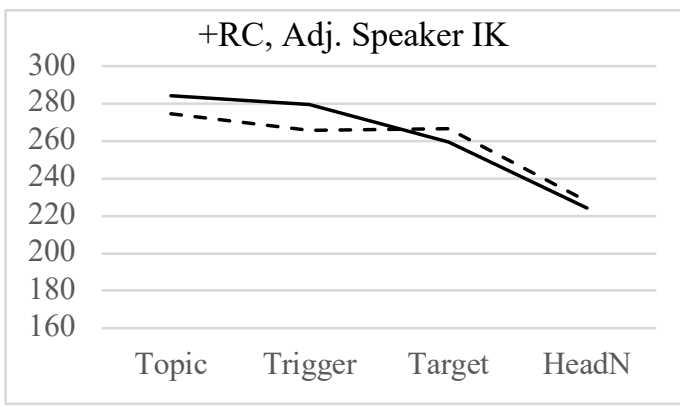

Adjective condition

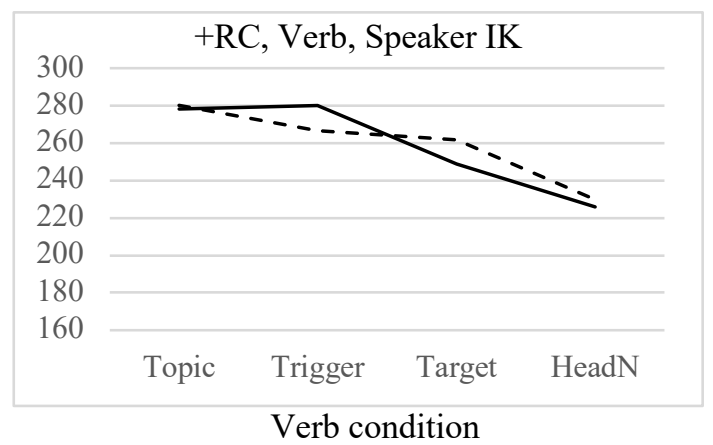

Speaker IK (attributive)

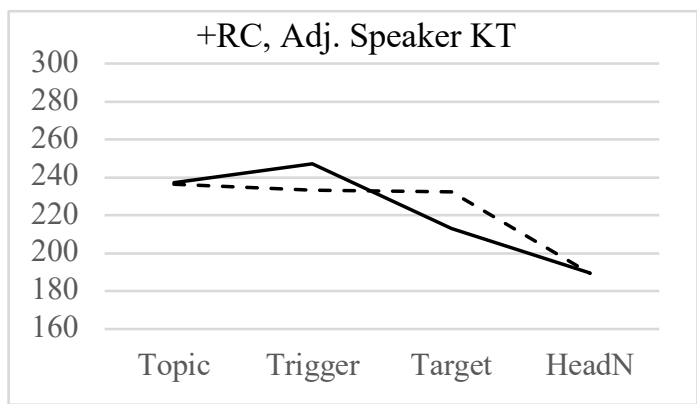

Adjective condition

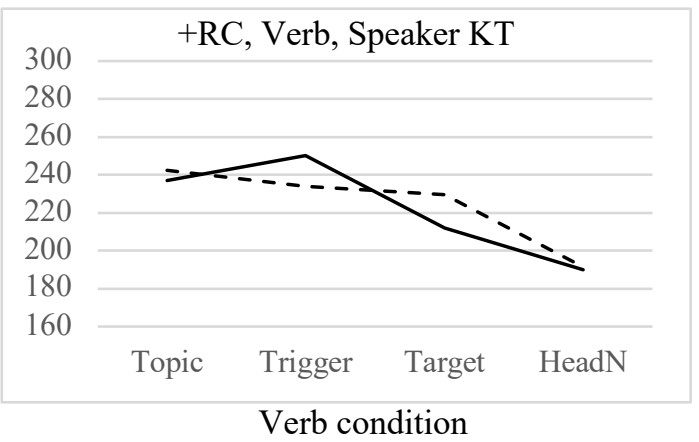

Speaker KT (attributive)

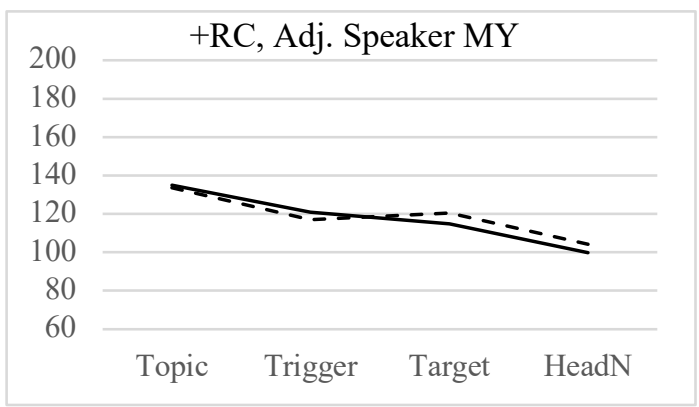

Adjective condition

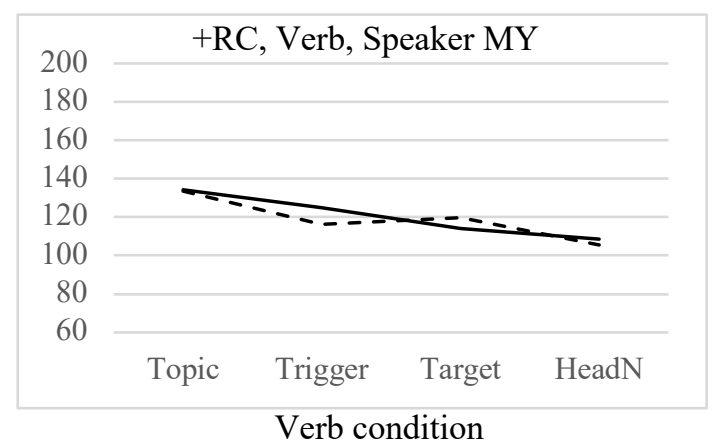

Speaker MY (attributive) 


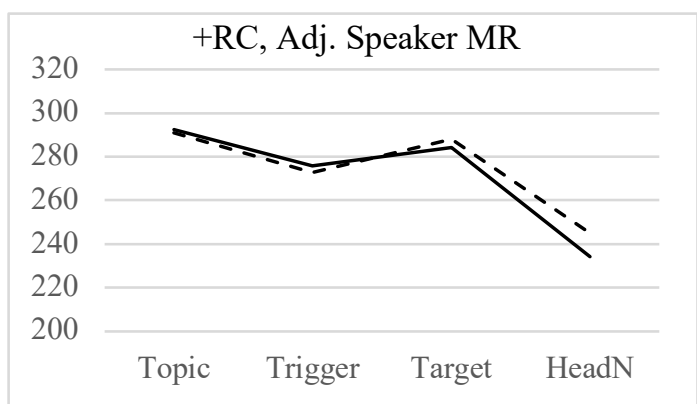

Adjective condition

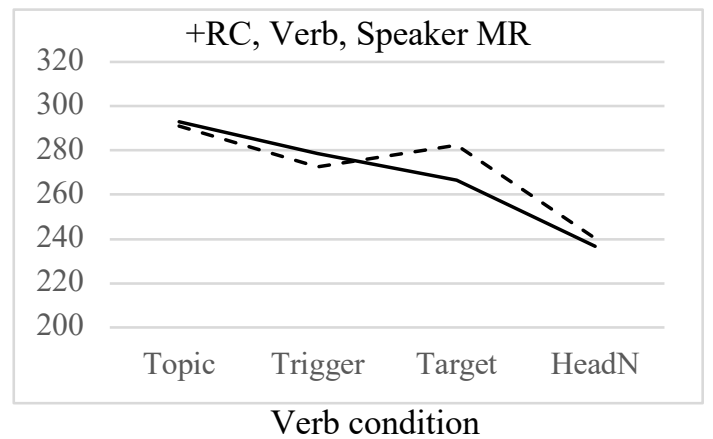

Speaker MR (attributive)

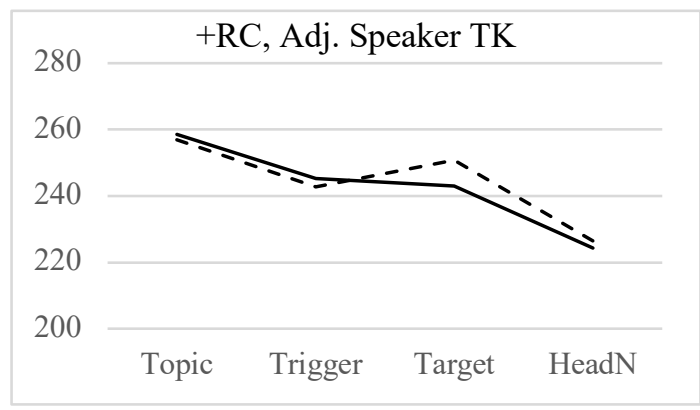

Adjective condition

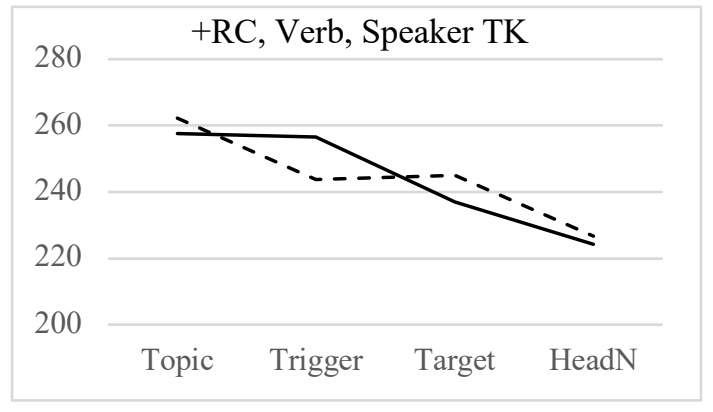

Verb condition

Speaker TK (attributive)

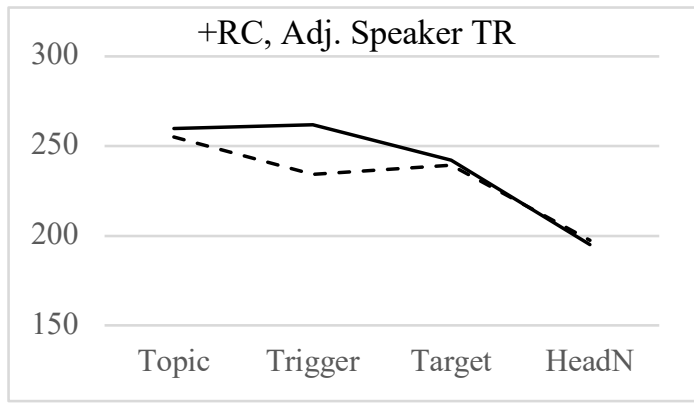

Adjective condition

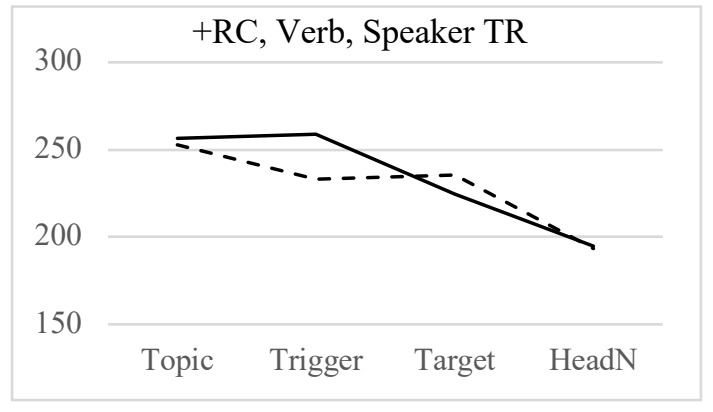

Verb condition

Speaker TR (attributive)

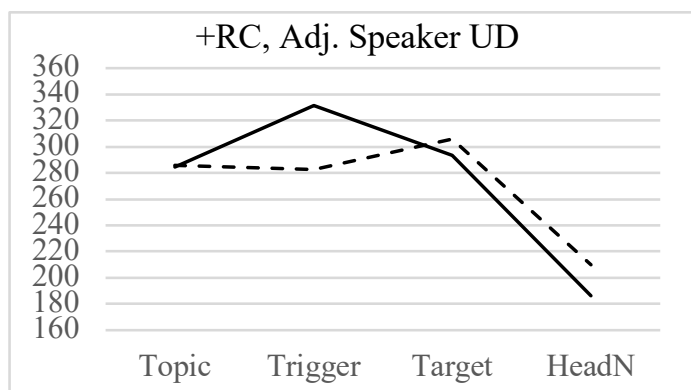

Adjective condition

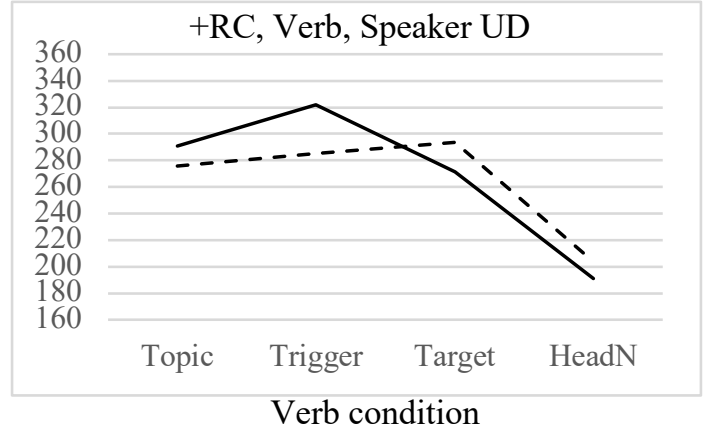

Speaker UD (attributive)

To summarize, we have observed much inter-speaker variation in adjectives in the relative clause 
condition, with some speakers not showing downstep, whereas the presence of downstep is much more robust with verb targets in the relative clause condition. In the non-relative clause condition, we do not find this difference between adjectives and verbs; consistent downstep is found with both targets. Put together with the results of Hirayama and Hwang (2016), the pattern is the following. First, downstep may be blocked in adjective targets when they modify the head noun within an NP, whether they are in the past tense form (this study) or in the non-past tense form (Hirayama and Hwang 2016). Second, downstep is not blocked (a) in adjectives in the predicate position (this study), (b) in verbs in the relative clause modifying a head noun and in the predicate position (this study), and (c) in nouns modifying a head noun (Hirayama and Hwang 2016). In other words, adjectives used in attributive modification (i.e., modifying a noun, whether they are in the past form or in the non-past form), may block downstep, whereas nouns and verbs in the same position do not. In addition, all these categories do not block downstep when they are used predicatively.

Why should that be the case? Specifically, why is downstep blocked in adjectives in attributive modification? We present a possible explanation related to phrasing. In all instances involving attributive modification, the test phrases in this study and Hirayama and Hwang (2016) consisted of NPs in which two phrases (differing in category) individually modify the head noun, i.e., $\left[X_{1}\left[X_{2} N\right]\right]$, with the target of the downstep in the second phrase $\mathrm{X}_{2}{ }^{2}$ Since downstep marks the Major Phrase/Intonation Phrase, we interpret the blocking of downstep as showing a break in the phrase $\left[\mathrm{X}_{1}\left[\mathrm{X}_{2} \mathrm{~N}\right]\right]$ that would otherwise constitute a single phrase. In particular, a phrase break is inserted between $\mathrm{X}_{1}$ and $\mathrm{X}_{2}$ due to the unnatural flow created between them.

We propose two possibilities as the reason for the unnatural flow. One is a violation of the order of attributive modifiers expected for an NP. Watanabe (2017) argues that there is a certain natural order in Japanese (like in English, where, for example, a small red ball is expected, not ? a red small ball). This order was respected in $\left[\mathrm{N}_{1}-n o\left[\mathrm{~N}_{2}-n o \mathrm{~N}\right]\right]$ but not always in $\left[\mathrm{A}_{1}\left[\mathrm{~A}_{2} \mathrm{~N}\right]\right]$ in the test phrases used in Hirayama and Hwang (2016) and this study (assuming that the order should be respected when $A$ is in the past-tense form as well), hence a boundary was inserted before $A_{2}$, blocking downstep. Verbs modifying a head noun $\left[\mathrm{V}_{1}\left[\mathrm{~V}_{2}\right.\right.$ $\mathrm{N}]$ ] presumably do not participate in this natural ordering constraint, and thus they do not block downstep. However, if the order constraint comes from semantic naturalness in general, we should note that our test phrases involving verbs may also violate the constraint because they include somewhat unnatural sequences. Also, the phrases involving target adjectives in this study have a verb in the trigger position, i.e., [V [A N]], and it is unclear what predictions should be made for a sequence of words of different categories. Even so, downstep may be blocked by A in that case. Therefore, this explanation based on the order violation in attributive modification cannot fully account for the data.

Alternatively, a better explanation may lie in how words in the same category can be combined in Japanese for combinations of $\mathrm{A}, \mathrm{N}$, and $\mathrm{V}$. Recall that words in the same category are used sequentially in the test phrases $\left[\mathrm{X}_{1}\left[\mathrm{X}_{2} \mathrm{~N}\right]\right]$ (i.e., [ $\left.\mathrm{N}_{1}-n o\left[\mathrm{~N}_{2}-n o \mathrm{~N}\right]\right]$, [V/A $\left.\left[\mathrm{A}_{2} \mathrm{~N}\right]\right],\left[\mathrm{V}_{1}\left[\mathrm{~V}_{2} \mathrm{~N}\right]\right]$ ). In Japanese, $\mathrm{N}$ and $\mathrm{V}$ can easily make compounds (noun-noun compounds and verb-verb compounds). Even introductory textbooks on Japanese linguistics have a section on compounds of these types (e.g., a section about V-V compounds in Tsujimura 2014: ff. 184). This may also show that these compounds with $\mathrm{N}$ and $\mathrm{V}$ are productive. In contrast, adjective-adjective compounds do not appear to be as common. While there are some (e.g., atsukurushii 'hot and stuffy,' amazuppai 'sweet and sour'), it appears that one cannot easily think of many. Nor do they appear to be so productive; those examples readily available are in fact found in the dictionary and thus might be analyzed as lexicalized units; we have the impression that compounds cannot be made with adjectives as productively as with verbs and nouns. If our intuition is correct that A-A compounds are not so readily available whereas N-N compounds and V-V compounds are, speakers may find the sequences of the same category in $\left[\mathrm{X}_{1}\left[\mathrm{X}_{2} \mathrm{~N}\right]\right]$ natural if the $\mathrm{X}$ is $\mathrm{V}$ or $\mathrm{N}$, since they have the knowledge that such words can freely occur in sequence; this knowledge is activated when they read the sequence, whereupon they can combine the entire $\left[\mathrm{X}_{1}\left[\mathrm{X}_{2} \mathrm{~N}\right]\right]$ as a single phrase without a problem. On the other hand, they may find it harder to interpret the sequence if it involves A, since they do not always expect two As in a row to make a single concept. This knowledge makes them stumble to make a single phrase of $\left[\mathrm{A}_{1}\left[\mathrm{~A}_{2} \mathrm{~N}\right]\right]$ when reading it. As a result, they may insert a boundary before $\mathrm{A}_{2}$. In the case of [V [A N]], by the same token, a sequence of $\mathrm{V}$ and $\mathrm{A}$ as a combined concept may not be as common in their knowledge, which makes it hard for them to

${ }^{2}$ The right-branching-ness does not explain the blocking because downstep may or may not occur in the same syntactic structure. 
make a single phrase of the entire NP, and thus they may insert a boundary between the V and A.

\section{Conclusion}

This paper investigated whether the relative clause boundary blocks downstep in Japanese. The hypothesis was motivated from two sources. One is the literature on the syntax-phonology interface and downstep in Japanese, in which it has been proposed that certain syntactic boundaries may block downstep (e.g., Ishihara 2016, Selkirk and Tateishi 1991). The other was the finding of Hirayama and Hwang (2016) that adjectives block downstep whereas nouns do not; we speculated that the difference was speculated to be due to the fact that adjectives project a relative clause whereas nouns do not.

In order to test this hypothesis, a production experiment was conducted with ten speakers. The results of the statistical analyses suggest that relative clause boundary does not block downstep. We found inter-speaker variation in phrases involving adjective targets, whereas phrases involving verb targets showed a consistent occurrence of downstep. Since downstep robustly occurred in the verb condition, the relative clause boundary per se does not block downstep at any rate.

Taken together with the results of Hirayama and Hwang (2016), the pattern emerged that adjectives in attributive modification (whether non-past tense or past tense forms) may block downstep, whereas downstep occurs in nouns and verbs in the same position and adjectives and verbs in the predicate position. We propose that this may be explained by assuming speakers' knowledge of the behavior of words of these syntactic categories when occurring in sequence that is activated when they pronounce the phrase. Nouns and verbs are readily available as a combined concept in Japanese such that they are robustly found in compounds, for example, and thus it is easy for them to form a single phrase when they occur in a sequence as in the test phrases $[\mathrm{N}-n o[\mathrm{~N}-n o] \mathrm{N}]$ and $[\mathrm{V}[\mathrm{V} \mathrm{N}]]$. On the other hand, adjectives are not as common when combined, which makes it harder for the speaker to make a single phrase of $\left[\mathrm{V} / \mathrm{A}_{1}\left[\mathrm{~A}_{2} \mathrm{~N}\right]\right]$ and thus they may insert a boundary before $\mathrm{A}_{2}$, resetting the domain for downstep.

\section{Appendix}

Below are the test sentences used in the experiment.

Relative clause present before the target phrases

(1) Adjective in the target, accented in the trigger
Topic
Trigger
Target
head $N$
a. áni-wa [[niránda $]_{\mathrm{RC}}$
[[darúkatta $]_{\mathrm{RC}}$
magó]] $]_{\mathrm{NP}}$
brother-TOP stare(v).PAST tired(ADJ).PAST grandchild COMP
'(My) brother said a grandchild who stared disfavourably and was tired.'
b. áni-wa $\left[[\text { nayánda }]_{\mathrm{RC}} \quad\left[[\text { nibúkatta }]_{\mathrm{RC}} \text { magó }\right]\right]_{\mathrm{NP}}$ to
'(My) brother said a grandchild who worried and was slow.'
brother-TOP worry(v).PAST slow(ADJ).PAST grandchild COMP say.PAST

(2) Adjective in the target, unaccented in the trigger

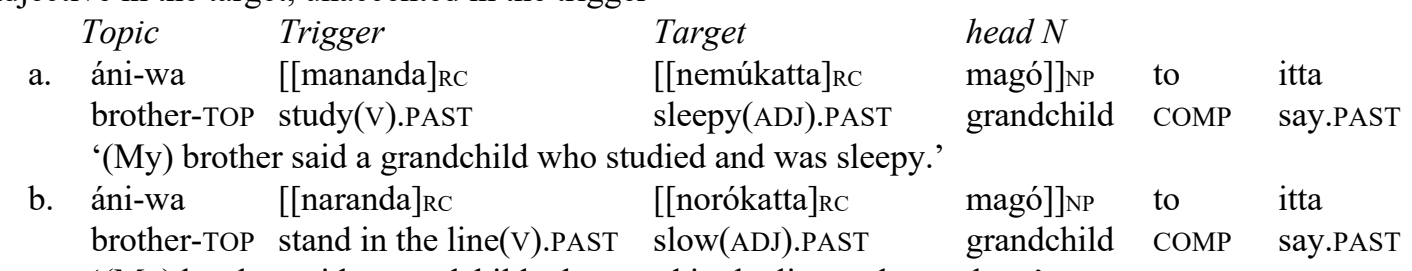

'(My) brother said a grandchild who stood in the line and was slow.' 
(3) Verb in the target, accented in the trigger
Topic
Trigger
Target
head $N$

a. áni-wa $\quad\left[[\text { najínda }]_{\mathrm{RC}} \quad\left[[\text { niránda }]_{\mathrm{RC}}\right.\right.$

magó] $]_{\mathrm{NP}}$ to itta

brother-TOP adjust(v).PAST stare(v).PAST grandchild COMP say.PAST

'(My) brother said a grandchild who got adjusted themselves and stared difavourably.'
b. áni-wa $\quad\left[[\text { najínda }]_{\mathrm{RC}} \quad\left[[\text { nayánda }]_{\mathrm{RC}} \text { magó }\right]\right]_{\mathrm{NP}}$ to itta brother-TOP adjust(v).PAST worry(v).PAST grandchild COMP say.PAST '(My) brother said a grandchild who got adjusted themselves and worried.'

(4) Verb in the target, unaccented in the trigger
Topic
Trigger
Target
head $N$
a. áni-wa
$\left[[\text { megunda }]_{\mathrm{RC}} \quad\left[[\text { niránda }]_{\mathrm{RC}}\right.\right.$
magó] ]NP to
itta
brother-TOP give alms(v).PAST stare(v).PAST
grandchild COMP
b. áni-wa $\left[[\text { megunda }]_{\mathrm{RC}}\left[[\text { nayánda }]_{\mathrm{RC}} \text { magó }\right]\right]_{\mathrm{NP}}$ to itta brother-TOP give alms(v).PAST worry(v).PAST grandchild COMP say.PAST '(My) brother said a grandchild who did alms and worried.'

Relative clause absent before the target phrases: trigger in the subject and target in the predicate VP.

(5) Adjective in the target, accented in the trigger
Topic
Trigger
Target

a. áni-wa [magó-ga nemúi]

brother-TOP grandchild-NOM sleepy(ADJ).NONPAST

'(My) brother said the grandchild is sleepy.'
b. áni-wa [mamé-ga nigái]
brother-TOP bean-NOM bitter(ADJ).NONPAST COMP Say.PAST

'(My) brother said the bean is bitter.'

(6) Adjective in the target, unaccented in the trigger
Topic
Trigger
Target
$\begin{array}{lll}\text { a. áni-wa } & \text { [mee-ga } & \text { nemúi] } \\ \text { brother-TOP } & \text { niece-NOM } & \text { sleepy( }\end{array}$
sleepy(ADJ).NONPAST COMP say.PAST
'(My) brother said (his) niece is sleepy.'
b. áni-wa [nirá-ga nigái]
bitter(ADJ).NONPAST COMP Say.PAST

brother-TOP leek-NOM bitter
'(My) brother said the leek is bitter.'

(7) Verb in the target, accented in the trigger
Topic
Trigger
Target
a. áni-wa [magó-ga nirámu]
to itta
'(My) brother said the grandchild stares (at him) disfavourably.'
b. áni-wa [magó-ga nayámu] to itta
brother-TOP grandchild-NOM worry(V).NONPAST COMP say.PAST

'(My) brother said the grandchild worry.'

(8) Verb in the target, unaccented in the trigger
Topic
Trigger
Target

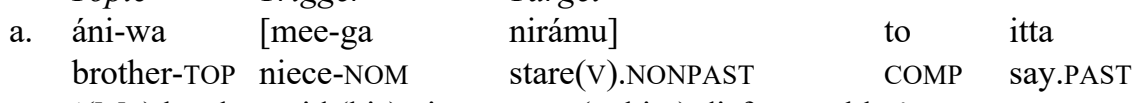

'(My) brother said (his) niece stares (at him) disfavourably.' 

b. áni-wa $\quad[$ mee-ga
brother-TOP niece-NOM
nayámu]
worry(v).NONPAST
$\begin{array}{ll}\text { to } & \text { itta } \\ \text { COMP } & \text { say.PAST }\end{array}$

'(My) brother said (his) niece worries.'

\section{References}

Hirayama, Manami and Hyun Kyung Hwang. (2016). Downstep in Japanese revisited: Lexical category matters. Poster presented at the 14th Conference on Laboratory Phonology.

Igarashi, Yosuke. (2015). Intonation. In Haruo Kubozono (ed.), Handbook of Japanese Phonetics and Phonology. Berlin: de Gruyter Mouton, 525-568.

Ishihara, Shinichiro. (2015). Syntax-phonology interface. In Haruo Kubozono (ed.), Handbook of Japanese Phonetics and Phonology. Berlin: de Gruyter Mouton, 569-618.

Ishihara, Shinichiro. (2016). Japanese downstep revisited. Natural Language and Linguistic Theory 34, 1389-1443.

Ito, Junko and Armin Mester. (2013). Prosodic subcategories in Japanese. Lingua 124, 20 - 40.

Kubozono, Haruo. (1989). Syntactic and rhythmic effects on downstep in Japanese. Phonology 6(1): 39-67.

Kuno, Susumu. (1973). The Structure of the Japanese Language. Cambridge: MIT Press

Pierrehumbert, Janet and Mary Beckman. (1988). Japanese Tone Structure. Cambridge: MIT Press.

Poser, William. (1984). The Phonetics and Phonology of Tone and Intonation in Japanese. Ph.D. dissertation, MIT.

Selkirk, Elisabeth and Koichi Tateishi. (1991). Syntax and downstep in Japanese. In C. Georgopoulos and Roberta Ishihara (eds.), Interdisciplinary Approaches to Language. Dordrecht: Kluwer, 519-543.

Tsujimura, Natsuko. (2014). An Introduction to Japanese Linguistics (3rd ed.). Malden, MA: Wiley-Blackwell.

Watanabe, Akira. (2017). Attributive modification. In Masayoshi Shibatani, Shigeru Miyagawa, and Hisashi Noda (eds.) Handbook of Japanese Syntax. Berlin: De Gruyter Mouton, 783-806.

$\mathrm{Xu}$, Yi. (2013). ProsodyPro - A Tool for Large-scale Systematic Prosody Analysis. In Proceedings of Tools and Resources for the Analysis of Speech Prosody (TRASP 2013), Aix-en-Provence, France. 7-10. 